\title{
TRADIÇAO E MODERNIDADE
}

\section{A PROPÓSITO DE PROCESSOS DE TRABALHO NA AMAZÔNIA*}

\author{
Edna Castro**
}

\section{Introdução}

Este artigo propõe-se a discutir a noção de trabalho a partir de observações sobre a diversidade de processos de trabalho que, embora estreitamente relacionados, têm sido tratados separadamente pela literatura sobre o assunto. Trata-se de examinar, dentro das modalidades de organização da produção encontradas na Amazônia contemporânea, alguns aspectos do trabalho desenvolvido por populações tradicionais ou organizadas em unidades de pequena produção familiar. Mas também o trabalho assalariado, organizado em médias e grandes empresas. Pretendemos em especial tecer considerações sobre os padrões modernos de gestão do trabalho em empresas de grande porte do setor mínerosiderúrgico e sobre as formas de articulação empreendidas com os atores anteriormente citados.

\footnotetext{
* Esta comunicação foi escrita no âmbito da Pesquisa "Transformações nas Relações de Trabalho na Amazônia, Território e Natureza”, realizada com apoio do Convênio CAPES-COFECUB. Agradeço os comentários de Rosa Acevedo Marin e Christian Azais, nas sessões de trabalho conjunto, ao longo da pesquisa, e as contribuições críticas de Leila Blass por ocasião da apresentação do tema, no Seminário Temático Trabalho, trabalhadores e sindicatos: desafios teóricos, por ela coordenado, no XXI Encontro Anual da ANPOCS, realizado em Caxambu/MG, outubro de 1997.

** Dr ${ }^{\mathrm{a}}$. em Sociologia, Professora e Coordenadora do Núcleo de Altos Estudos Amazônicos/UFPA.
} 
O ritmo acelerado das mudanças sociais, econômicas e ambientais encontradas nessa região tem a nosso ver, nas transformações no mundo do trabalho, um locus privilegiado para análise. As estruturas de produção tradicionais, em diversos setores - agricultura, indústria e serviços -, foram alteradas, em graus diversos e com intensidade variada. Por outro lado, nos últimos 20 anos consolidou-se um conjunto de empresas de grande porte, cuja gestão tem objetivado responder aos padrões de exigência do mercado mundial, mercados estes pela competição interfirmas e intercadeias produtivas. Mas, apesar de tais mudanças, permanecem e, em certas situações até mesmo se reforçam, formas tradicionais de trabalho. No campo das relações sociais de produção, reafirmam-se os procedimentos de dominação paternalistas, como por exemplo o aviamento. Perguntamos, portanto, como esses mundos aparentemente separados, tocam-se, interagem nos circuitos de produção e de comercialização e geram riquezas que reproduzem a estrutura desigual da sociedade. Por outro lado, interrogamos o conceito de trabalho, na sua vinculação clássica à relação salarial, pois pouco nos ilumina na compreensão de atividades tradicionais reatualizadas nessa região, apesar do avanço da fronteira industrial.

Entender situações como essa parece colocar-se hoje como crucial. A nosso ver, é à noção de trabalho que se deve retornar. Uma volta aos clássicos ${ }^{1}$, certamente, pois a sociologia e a economia do trabalho estiveram muito direcionadas, nas últimas décadas, à análise de situações de trabalho a partir das relações salariais, Interrogando processos e padrões de organização que configurassem a emergência ou mesmo a consolidação de modos de produção técnico e organizacionalmente mais avançados. $\mathrm{O}$ interesse também esteve - e ainda está - direcionado para entender a dinâmica do mercado de trabalho, mas com precisos cortes orientados às relações assalariadas, a atividades regulamentadas e formais, razão provavelmente da ainda reduzida teorização encontrada na literatura sobre o setor informal. Destacamos em especial lacunas na orientação teórica e de pesquisa, orientação que deveria dar conta do papel desempenhado pelo setor informal na crise de empregabilidade e na reprodução social.

\footnotetext{
${ }^{1}$ As fontes teóricas a que todos nós tivemos de ir para compreender o pensamento sociológico, consideram o conceito de trabalho como estruturante das interpretações sobre a sociedade capitalista. Em Marx a noção não só é fundamental como uma síntese, mas que ao mesmo tempo abre as perspectivas teóricas da interpretação sobre os processos de concentração e acumulação. Mas é em Weber, na teoria da ação, e do seu sentido, que a noção de trabalho é chave no entendimento da cultura e do desenvolvimento do capitalismo. Para Durkheim, restringimo-nos ao aporte clássico das análises da divisão social do trabalho, e de seu papel nos sistemas de representações, nas sociedades modernas, que influenciaram por muito tempo as novas interpretações.
} 
Os estudos sobre o trabalho tiveram a atenção voltada sobretudo à compreensão das mudanças, dos regimes de acumulação e de suas crises, procurando acompanhar de perto a emergência de novas tecnologias e de processos de trabalho. Acabou-se assim deixando de fora um debate extremamente interessante sobre a pertinência e a reprodução, apesar da modernização, de saberes de populações tradicionais sobre recursos naturais e suas estratégias de uso e de exploração comercial. E no entanto esses saberes têm atualizado processos de trabalho e padrões de gestão que continuam a compor o cotidiano da produção de muitas regiões, como a Amazônia. Mas também estão presentes na quase totalidade dos países dos continentes africano, asiático e sul-americano, conforme literatura produzida sobretudo no âmbito da etnociência ${ }^{2}$. Cabe lembrar também a presença dos grupos autóctones que mantêm padrões tradicionais, em processos de afirmação étnica, encontrados inclusive em países da América do Norte.

O exame das formas tradicionais de trabalho pode trazer mais clareza à explicitação da noção de trabalho, justamente porque permite um distanciamento, no tempo e no espaço, do padrão dominante da relação salarial, permitindo avançar em uma formulação mais abstrata .

\section{Trabalho, território e tempo em grupos tradicionais}

A longa história da humanidade é também a da transformação da natureza. A capacidade do homem em alterar suas relações com a natureza, ao mesmo tempo em que transforma a própria natureza, esteve sempre orientada para o território e seus recursos. $\mathrm{O}$ avanço da economia mundial ocorreu com base na exploração de recursos naturais e na busca incessante de novas tecnologias para a apropriação da natureza. Cada momento representa o predomínio de certo padrão tecnológico que, combinado às formas de organização do trabalho, responde pelo desenvolvimento

\footnotetext{
${ }^{2}$ Ver trabalhos nessa perspectiva de Anne Luxereau: Usos, representações e evolução da biodiversidade entre os Haoussa da Nigéria; de Philippe Descola: Ecologia e Cosmologia; de Marie Roué: Novas perspectivas em etnologia: "saberes tradicionais" e gestão dos recursos naturais. E ainda, numa ótica menos antropológica mas que desenvolve também uma perspectiva que integra sociedade e natureza, ver: Patrice Levang, Geneviéve Michon, Hubert de Paresta, Philippe Guizol e Pabienne Mary: Conservação dos recursos naturais e desenvolvimento: as agroflorestas de Damar no Pesisir, Sumatra. In: Castro, E, \& Pinton, F (1998) Faces do Trópico Úmido. CEJUP/UFPA, Belém.

${ }^{3} \mathrm{O}$ trabalho entendido em sua versão mais aproximada ao mercado, no aparte da economia do trabalho.
} 
histórico do capitalismo. O processo de acumulação e valorização foi continuamente alimentado pela descoberta de novos territórios incorporados como fronteiras de recursos. Padrões tecnológicos e fronteiras de recursos têm sido, de forma mais ou menos explícita, relacionados por autores clássicos na procura de explicações sobre novos ciclos de acumulação de capital. Por outro lado, as mudanças estruturais apontam a redução de insumos tradicionais em setores de ponta e a descoberta de novos materiais. O que vai de encontro a uma concepção de valor atribuída não mais aos recursos naturais convencionais mas à própria natureza, enquanto laboratório para a descoberta de novas fontes de energia, novas mercadorias. A valorização da biodiversidade desafia o avanço tecnológico para orientar pesquisas e aplicações sobre materiais e produtos estratégicos fundamentais para alimentar novos ciclos industriais.

Intensifica-se na Amazônia a busca desses recursos (minério, madeira, pescado, sementes e frutas, plantas medicinais, entre outros), por parte das empresas nacionais e multinacionais, e prosseguem as iniciativas de pesquisas. Vem observando-se uma ampliação das atividades produtivas com relativa diversificação de produtos para fins industriais, embora essas unidades industriais localizem-se fora da região, gerando aí grande parte dos ganhos econômicos ${ }^{4}$. Essa ampliação é em parte decorrente dos resultados produzidos por pesquisas florestais, zoológicas e genéticas, orientadas portanto para obter vantagens no campo da biogenética. Os novos paradigmas do progresso tecnológico certamente provocarão impactos no território regional, e o Brasil poderia certamente engajar-se na produção de conhecimento e de informações especializadas sobre a biodiversidade. Mas o que se observa são os riscos e uma dinâmica que aponta para a reprodução de desequilíbrios regionais. Um rearranjo entre estruturas de produção de conhecimento instaladas em outras regiões do país e no exterior, com elevado padrão científico e tecnológico, e que tendem a incorporar vantagens nesse domínio. Esse tema é fundamental e desafia o acompanhamento de seus desdobramentos na história contemporânea vivida por atores locais dessa região. Neste artigo,

\footnotetext{
${ }^{4} \mathrm{O}$ debate atualizado sobre as relações de trabalho assalariadas e as mudanças que vêem ocorrendo, resultando em desemprego e exclusão social, tem alimentado a polêmica sobre as estratégias neoliberais em aplicação e os efeitos da desregulamentação do mercado de trabalho. É elucidativo também sobre as tensões reveladas pelas diferentes interpretações no âmbito da sociologia e da economia do trabalho. Sobre o assunto ver Oliveira, F: 1998; Abreu, M. et al.:1997; Casassus, C. M: 1994; Womack, L-P, Jones, D.P; 1992.
} 
contentar-nos-emos apenas em assinalar tal problema, uma vez que interfere tangencialmente na reprodução dos processos tradicionais de trabalhos ${ }^{5}$.

Uma redefinição das relações de trabalho também se inclui no rol de mudanças, razão pela qual interessa saber como se dão tais mudanças, o que emerge de novo e quais as formas produtivas que são reificadas no âmbito das relações de dominação. Ora, o trabalho que recria continuamente essas relações, reúne aspectos visíveis, tangíveis e simbólicos. O trabalho está longe de ser uma realidade simplesmente econômica. Nas sociedades tradicionais, no seio da pequena produção agroextrativista, o trabalho é representado por um caráter único, ou seja, reúne nos elementos técnicos e de gestão o mágico, o ritual, enfim, o imaginário coletivo recriado no mundo simbólico. Inúmeros estudos desenvolvidos pela ecologia e pela etnoecologia sobre os ameríndios têm mostrado nas últimas décadas a diversidade e a extensão dos saberes e das técnicas desenvolvidas para apropriar-se de recursos do meio ambiente e adaptá-los a suas necessidades. Essa adaptação a um meio ecológico de alta complexidade realiza-se graças aos saberes acumulados sobre o território ${ }^{6}$ e às diferentes formas pelas quais o trabalho é realizado, que depende do domínio de técnicas de caça, de pesca, de plantio, de identificação na mata de recursos que alimentam seu sistema de preservação da saúde, de curas, de manejo de espécies, de defesa dos membros do grupo, etc.

É importante reconhecer que cada sociedade, em fases particulares de seu desenvolvimento, produz seus processos de trabalho, de transformação da natureza e de apropriação dos recursos naturais para sua reprodução social e cultural. O trabalho é esse conjunto de manifestações dos humanos face à natureza, de atividades materiais e simbólicas. Enfim, nossa hipótese é a de que a noção de trabalho, nas formas mais diretas de sua execução, como aquele presente em certo campesinato da Amazônia,

\footnotetext{
${ }^{5}$ Nas reflexões que seguem a propósito dos processos de trabalho tradicionais utilizaremos resultados de pesquisas anteriores realizadas com grupos diferentes que fazem parte de um campesinato mais antigo da Amazônia, cujas vivências atuais reatualizam processos de identidade étnica e saberes sobre a natureza, a exemplo de grupos de comunidades negras rurais - quilombolas -, agricultores, pescadores e coletores (ver sobre o assunto: Acevedo, R. e Castro, R.: 1998 e Relatórios da pesquisa Mapeamento de comunidades negras rurais no Estado do Pará: 1999-NAEA/UFPA).

${ }^{6} \mathrm{O}$ território é o espaço sobre o qual um certo grupo garante aos seus membros direitos estáveis de acesso, de uso e de controle sobre os recursos e sua disponibilidade no tempo. Como diz Godelier, o território reivindicado por dada sociedade constitui o conjunto de recursos que ela deseja e se sente capaz de explorar sob condições tecnológicas (1984). Mas todas as atividades produtivas contém e combinam formas materiais e simbólicas com as quais os grupos humanos agem sobre o território.
} 
faz parte de um sistema mais amplo de ações e de estratégias indissociáveis de outras atividades do cotidiano, bem como das relações de parentesco, políticas e mesmo religiosas.

Além disso, se reconhecemos essa fantástica diversidade empírica de sociedades e, portanto, de processos de trabalho, construídas diferentemente em épocas diversas, teremos de constatar o quanto a noção de trabalho deve incorporar esse múltiplo, complexo, da ação humana sobre o território. Afinal de contas, não é aí que se fundam os princípios da relação cultura-natureza, cara à análise clássica das ciências sociais? Ainda que existam representações simbólicas e míticas que perpassem as diferentes formas de organizar o trabalho, cada uma delas defronta-se com as capacidades e os limites dos saberes e dos interesses de cada grupo, de suas formas de agir sobre o território e de se apropriar de recursos de acordo com padrões de seletividade pertinentes a cada grupo.

Diegues chama atenção para a unicidade que vê nas sociedades tradicionais, entre as técnicas de produção e o campo do simbólico. Procura demonstrar isso na relação que percebe entre a atribuição de tempo de pescar, de caçar e de plantar e os mitos ancestrais em sociedades indígenas, como os caiçaras do litoral sul do país e os ribeirinhos amazonenses (1994). Em toda a orla costeira do nordeste paraense e nos seus estuários, pescadores de peixe e camarão, ou tiradores de caranguejo, apóiam-se nos saberes sobre o tempo, as marés, os estoques e cardumes, as fases da lua e a ação das chuvas, para explicar seus processos de trabalho, a lógica de suas técnicas de captura e a invenção de sua vida social. O rio e o ciclo de águas são incorporados como dimensão fundamental da vida entre os povos das águas da Amazônia. Os anciãos recorrem à imagem de rios, igarapés e lagos, como percurso pelos campos da memória onde estão depositadas as lembranças. A concepção do tempo social e do tempo individual encontra explicações no cruzamento com o tempo da natureza: tempo de caçar, de pescar, de coletar, de botar roça. Encontramos, entre negros remanescentes de quilombos no rio Trombetas e camponeses de comunidades negras da região Bragantina, uma integração entre a vida econômica e social do grupo, em que o mundo do trabalho faz parte da cadeia de sociabilidade e a ela é indissociavelmente ligado. Facilitam encontros interfamiliares, realização de festas, perpetuação de rituais e outras modalidades de trocas não econômicas. Em regiões próximas de grandes cidades como Belém e Manaus, ou nas cabeceiras de rios no extremo 
ocidente da Amazônia brasileira, encontramos portanto variações de uma economia agroextrativista, reproduzindo-se no meio de outros sistemas de produção. A caça, a pesca e a coleta de seringa, castanha e de outras espécies florestais estão associadas à agricultura. O esforço do trabalho é organizado em função da acessibilidade de terra e de recursos.

Outra tendência aparece pela constituição de territórios sob o controle das empresas . O que está em jogo não é o território em si, espaço físico apropriado ou pretendido, mas a territorialidade enquanto exercício de um domínio que se realiza ou se projeta pelas relações políticas, portanto historicizadas. Nesse sentido, a leitura sobre as tendências expansionistas e as práticas empresariais de controle sobre espaços - promotoras de mudanças importantes - tem revelado a constituição de novas territorialidades por parte de empresas. A intervenção programada por atores empresariais é contestada por forças sociais portadoras de outras territorialidades. No fundo trata-se de um movimento de confronto entre espaços, de formas diferentes de domínio e de concepção coletiva do espaço. Identicamente, são percepções do tempo diferentes. A discussão sobre as estratégias das empresas e sua relação com outros atores sociais suscita a descoberta de novos campos de conflito em torno da questão ambiental.

\section{Processos de trabalho e saberes tradicionais}

Processos de trabalho com tecnologias simples e formas particulares de gestão dos recursos naturais compõem o quadro singular das relações de trabalho em sistemas tradicionais, como os encontrados em sociedades indígenas, caboclas, em um campesinato antigo. Por outro lado, observase a mobilização de saberes sobre os recursos naturais e as possibilidades de gerar produtos do trabalho, por parte de populações ribeirinhas que trabalham em áreas de várzea ou de camponeses que trabalham e vivem em terras firmes. Uns e outros compõem o leque de grupos sociais

\footnotetext{
${ }^{7} \mathrm{Na}$ percepção corrente que separa a economia da sociedade, são introduzidos outros elementos de revalorizado da natureza pela lógica de mercado. Esse movimento atribui elementos complementares ao conceito de território. O ambiente mercadoria é visto pelo menos sob duas dimensões: a primeira corresponde aos recursos naturais convencionais, de antiga ou recente exploração na Amazônia; a segunda representada pelo potencial bioenergético contido na natureza. As empresas, de diferentes setores e tamanho, mantém estratégias tradicionais de domínio do território, muitas vezes integrando as atividades industriais à extrativistas. Caso em especial observado nas atividades madeireiras e de mineração.
} 
nomeados pelas principais atividades exercidas, embora fazendo parte de um campesinato polivalente - agricultores, agroextrativistas, seringueiros, pescadores, coletores e caçadores, garimpeiros, castanheiros, quebradeiras de coco, entre outras. São categorias de nomeação, nas quais se cruzam olhares sobre o outro e que pouco explicitam das especificidades do trabalho, de sua natureza e de suas formas. Pouco dizem sobre a complexidade dos processos identitários, as representações que os unem e as orientações de suas ações políticas. Muitas vezes os conflitos com outros atores sobre as formas de apropriação da terra e dos recursos provenientes da floresta e dos cursos d'água, base da sobrevivência desses grupos, não são suficientemente explicitados, embora bastante elucidativos dos saberes sobre o trabalho.

A literatura tem mostrado que essas populações conseguem distinguir diferenças mesmo sutis ou imperceptíveis talvez para pessoas de outra cultura sobre, por exemplo, elementos que compõem seu território e que exprimem o nível de percepção de sua complexidade. A capacidade de classificar segundo categorias os objetos reais importa numa construção de significados para o processo de comunicação. Os sistemas classificatórios dessas populações fazem prova do patrimônio cultural, sendo capazes de precisar sons da floresta e sua variação dependendo da hora do dia, se chove ou não, se há mais ou menos ventos, sinais identificados por vários autores já há várias décadas, ainda que a etnoecologia tenha experimentado um desenvolvimento mais recentes . A seleção do que plantar segue uma escala de preferência alimentar, combinando critérios de diversidade de gosto, de costume, de valor nutritivo e possibilidade de sucesso no plantio. A partir dessa escala de preferência e da importância que ocupam os gêneros resultantes da caça, da coleta, da pesca e do plantio, é possível entender aspectos importantes das relações desses povos com o território comum. Praticam uma estratégia de deslocamento familiar em função das fontes de aprovisionamento, que podem ser a caça e a pesca, mas também em função da presença de terras mais férteis para realizar seu roçado.

Ainda que não lhes seja possível dar explicação para uma série de fenômenos observados, as ações práticas funcionam pelas respostas que são dadas nas relações com a natureza, informando o processo de

\footnotetext{
${ }^{8}$ As duas vertentes fundadoras no conhecimento etnológico, cujos interesses centram-se na análise dos saberes tradicionais, como conhecimentos produzidos com um olhar externo ao grupo, diferenciamse pois a etnociência "acentua os aspectos cognitivos, e a ecologia cultural, centrada nos paradigmas de adaptação, são mais ou menos contemporânea da etnoecologia”. (Rouê: 1997).
} 
acumulação de conhecimento através das gerações. Há uma racionalidade na seleção daquilo que é socialmente acumulado, reciclado e socializado. Essas concepções da natureza, das águas e da floresta são difíceis de serem entendidas a partir dos valores das lógicas de reprodução que presidem a sociedade capitalista, fundados em princípios que negam a territorialidade e a etnicidade desses grupos e sobretudo suas modalidades de organizar o trabalho. São maneiras diversas de perceber, de representar e de agir sobre o território, concepções que subjazem às relações sociais. Trata-se de dois sistemas nos quais o técnico-econômico funciona sob normas diferentes e que dá resultados e efeitos também diferentes no meio ambiente. No caso de comunidades marcadas por identidades étnicas, representadas como o outro, esses elementos ideológicos e políticos resultam incompreensíveis para o conhecimento técnico-econômico pelos fortes traços de preconceito e estranhamento. A bagagem classificatória encontrada nos grupos do Trombetas, por exemplo, permite descrever com detalhes diferenças de tipos e de variações em uma mesma espécie ou entre espécies diferentes de plantas de terras firmes e de várzea, de peixes, de animais de caça etc... Suas falas são marcadas por analogias tecidas entre humanos e animais, entrecortadas de referências à vida na floresta ou mesmo de preceitos morais calcados em simbologias com seres não humanos.

A relação de povos tradicionais com a natureza manifesta-se no seu próprio vocabulário e nos termos que usam para traduzir sua vivência e adaptação aos ecossistemas. Revela também a compreensão do trabalho intimamente articulado à vida familiar, quer dizer, às relações de parentesco no interior do grupo. Neste artigo, porém, procura-se refletir sobre elementos que tragam maior visibilidade à natureza mesma do trabalho realizado, o lugar do trabalho nas representações de seus sujeitos, nos seus discursos.

Essa modalidade de vida encontra similitudes com povos da floresta de outros países, como comprovam inúmeros estudos desenvolvidos pelas várias correntes da etnociência e da antropologia cultural. Mais recentemente, a partir dos anos 70, têm sido valorizados os saberes de populações locais e indígenas sobre a natureza, mas com uma orientação bem nítida proveniente do debate sobre a preservação de ecossistemas e biodiversidade, objetivando valorizar esses saberes para gerir os recursos naturais, e evidentemente novos modalidades de comercialização. O interesse em adotar essa perspectiva começa a ser tema de inúmeras pesquisas que passam, muitas delas também, pelo financiamento de agências internacionais de desenvolvimento. Pode-se depreender que em contextos 
culturais diferentes os conflitos pela apropriação do território está na relação direta com a reprodução.

A luta pela terra não pode ser dissociada da luta pelo trabalho. E não é a forma salarial que se encontra em questão. Processos de mobilização empreendidos por grupos e que explicitam, nesses processos políticos, seus discursos e suas reivindicações, interpelam mais uma vez nossa compreensão sobre a noção de trabalho. Nesse campo, é possível perceber elementos de tradição e modernidade, como fundamento das lutas pela propriedade e posse da terra. Numa outra perspectiva, o Movimento dos Sem Terra, no nível nacional, de certa forma também faz parte, enquanto mediação política e com a sua extensa rede de articulação nacional e mesmo internacional, desse conjunto de grupos em vigília, que vagueiam em torno da reprodução da pequena produção, embora se depreendam de seu discurso elementos de um compromisso ou um encanto com a modernização da pequena agricultura. Essa idéia do moderno, do progresso, do controle técnico está presente nos discursos de pequenos produtores rurais. A mesma dimensão é encontrada na recente mobilização, por parte de grupos indígenas no Alto Purus e no Solimões (no Amazonas), em torno de uma reatualização da memória dos antepassados. Experimentam um movimento que pretende recuperar a identidade de outrora de seu grupo, via construção identitária através de processos políticos.

No Trombetas, membros dos grupos de remanescentes de quilombos comunicam-se entre si e recriam imagens, reconstruindo termos e enunciados, inspirados na natureza que os cerca. Com detalhes, identificam tipos diferentes de fauna e flora, sons, movimentos, odores, tempo de vida, suas formas, usos e funções e, como elemento importante no quadro de percepções, sua relação com a água. $\mathrm{O}$ verão traz consigo maior presença de peixe na dieta alimentar. Os pescadores defrontam-se com alterações na coloração da água, na profundidade do rio, nas mudanças de cardume e, com elas, a tarefa de seleção dos equipamentos segundo as preferências, antes de sair para pescar. Comprovam e conferem presenças e ausências de tipos de peixe. Essa atividade percorre o calendário anual, embora seja mais intensiva no verão. O rio Trombetas, seus afluentes e lagos, são cursos com variedades de peixes, e seus moradores os classificam segundo tamanho, cor, quantidade, características morfológicas e comportamentais da espécie, o que determina a seleção de técnicas apropriadas e as formas de captura. 


\section{Estado, território e conflitualidade}

Do ponto de vista do Estado, as estratégias voltadas para a Amazônia nas últimas décadas orientaram-se para o controle sobre a fronteira de recursos, incentivando a sua integração ao espaço econômico mundial. $\mathrm{O}$ exame da ação fundiária governamental demonstra como interessa ao Estado incorporar ao mercado nacional de terras, extensões crescentes do território por vias legais ou à margem de negociações consideradas legitimas. A principal evidência dessa intervenção manifesta-se no plano político, ao se examinar as ações programadas e os resultados que têm sido obtidos no domínio de territórios por parte de segmentos empresariais e de órgãos do Estado. Ainda que, no plano econômico, a apropriação de recursos naturais se apresente como condição da implantação de empreendimentos produtivos ou de infraestrutura. Esses processos políticos de domínio e controle de novas fronteiras não constituiriam elementos a ser considerados na discussão sobre mudanças nas formas de trabalho e no processo de produção?

Nas áreas de várzea do Médio Solimões, região formada por centenas de lagos, canais e paranás, concentra-se uma população que tem no trabalho da pesca seu principal meio de subsistência. Esses lagos constituem objeto de intensos e contínuos conflitos entre ribeirinhos e pescadores, principalmente na época de seca quando a pesca se tona mais produtiva, para certas regiões. A ação do estado potencializa muitas vezes os conflitos (McGrath, et al 1998). Recentemente, a partir da década de 80, constroemse novas institucionalidades, de um lado, devido às tensões e, de outro, pelo avanço do debate sobre a preservação de recursos hídricos e pesqueiros, com o movimento de preservação de lagos, em que a presença da CPT inicialmente no processo foi fundamental, vindo a ela juntar-se outras mediações sob a forma de ONGs. No âmbito do extrativismo do coco do babaçu, sobretudo na confluência dos Estados do Pará, Maranhão, Piauí e Tocantins, em especial no Bico do Papagaio, o trabalho de mulheres coletoras é afirmado como processos produtivos que vão da coleta ao beneficiamento do coco de babaçu em diversas linhas de produção artesanal - em especial na alimentar e na cestaria - e à comercialização. Os processos políticos expandem-se pelas vias tradicionais da organização sindical, mas sobretudo pelas novas institucionalidades que se afirmam em formas de organização do trabalho via cooperativas e associações de pequenas produtoras e através de processos de construção de identidades, enquanto castanheiras. Na pauta política desses grupos, observam-se discursos que religam trabalho enquanto esforço, fazer e viver a experiência prática da 
reprodução e de domínio do território com o qual eles, grupos tradicionais, estabelecem uma relação fundamental.

A identidade étnica representa para os grupos negros do Trombetas a substância de suas práticas associativas e a afirmação de suas concepções sobre o trabalho. O quilombo, opção extrema na conquista da liberdade, no passado, é na memória de hoje a expressão de um outro modo de vida, do trabalho em liberdade, em oposição ao trabalho escravo e ao regime de "servidão". O reconhecimento dos lugares ocupados na história do grupo permite refazer dimensões específicas de ser e existir enquanto camponês e negro. O território é fundamental à reprodução de sua existência e à manutenção de sua identidade. A permanência nesses sítios revela os diferentes planos da organização social, importante na análise das instituições sociais do grupo, guardando semelhança com os pontos descritos por Geertz (1986) sobre a cultura enquanto interpretação densa. Identificam-se duas dimensões históricas e fundamentais dessa ordem comunitária. A primeira diz respeito à forma de apropriação dos recursos, e a segunda refere-se à presença de práticas de trabalho na economia agroextrativa que articulam diversas esferas da vida social. A noção de nós, que traduz íntima identificação dos grupos domésticos com a comunidade núcleo mais amplo, em oposição aos outros que correspondem à externalidade dos grupos de fora, funda a territorialidade na região do Trombetas.

É extensa a área formada por vários municípios que circundam Belém, lugar de ocupação histórica de significativa população ribeirinha dedicada à atividade extrativa - madeira, açaí, outras frutas, cipós, plantas nativas de uso medicinal - em processos bastante diversificados. Os usos vão do caseiro ao industrial. A interação e as trocas econômicas com atores empresariais que exploram tais recursos são reeditadas até a atualidade, de acordo com processos de comercialização bastante complexos. Observase de forma mais clara como o trabalho desses grupos familiares, desempenhando atividades com processos de trabalho bastante artesanais e utilizando-se de instrumentos extremamente simples, pode fazer parte, ainda que na informalidade, de uma cadeia produtiva formada por pequenos, médios e grandes empreendimentos - serrarias, comércio, usinas de palmito ou processamento de outros alimentos, siderurgia, compensados. A análise das formas de articulação entre trabalhadores artesanais e as empresas de tais ramos tem trazido importantes contribuições para a elucidação desse mundo do trabalho. 


\section{Relações de trabalho tradicionais e articulação com grandes e médios empreendimentos}

As análises das estratégias empresariais adotadas por pequenas e médias empresas em relação à absorção de trabalhadores e às condições de realização do trabalho têm revelado a afirmação de formas arcaicas de dominação social, cujo universo simbólico encontra-se marcado por noções de paternalismo. Estudos sobre os trabalhadores das fábricas de castanha, de palmito, de madeira, de óleos e sabões apontam essa perspectiva de trabalho e lugar de dominação. Nas cidades de Belém e São Luís, os empreendimentos industriais mais recentes, instalados com financiamentos e incentivos fiscais, inauguram novos ramos produtivos, mas não necessariamente sob formas mais democráticas de relações de produção. Não são as grandes empresas responsáveis pela maior parte da relação salarial, mas são as pequenas e médias, cuja presença é mais significativa dada a quantidade de estabelecimentos, o volume de mão-de-obra empregado, os recursos que mobilizam e a extensão no território e dos recursos apropriados. Mas, do outro lado, encontram-se os grandes empreendimentos instalados sob modelo de enclave, voltados à exportação, como os projetos da MRN, ALBRAS, ALUNORTE, CVRD e ALUMAR. Em Manaus, centraliza-se um parque microeletroeletrônico com a presença das empresas multinacionais mais expressivas do setor. A lógica subjacente às Zonas Francas instaladas no mundo a partir de fins dos anos 60 foi de deslocamentos da produção, definindo outros espaços de criação do valor, assentados ainda no processo de multinacionalização da economia.

Os conflitos que colocam em confronto grandes e médios empreendimentos e pequenos produtores extrativos são generalizados. No movimento das frentes garimpeiras, encontra-se uma trajetória espacial marcada por tensões. Esse segmento social defrontou-se com inúmeras empresas de mineração, tendo garantido para si algumas lavras, contrariamente aos interesses de grandes e sólidas empresas ancoradas no território amazônico, como a CVRD e entidades representativas do empresariado, como o Instituto Brasileiro de Mineração (Ibram) e a Associação dos Mineradores do Ouro, Abamo. Os estudos sobre os processos de produção da madeira e do pescado na região, com linhas produtivas bem mais diferenciadas entre si do que poderíamos imaginar numa abordagem inicial, trazem à luz formas particulares de integração entre os processos tradicionais e o aproveitamento dos saberes mobilizados ao longo dessas atividades, por parte de unidades produtivas mais 
modernas, apesar das exigências de padrões de qualidade e de competitividade na atual dinâmica de mercado.

Numa outra perspectiva, espacial, observam-se as motivações de trabalho incentivando grupos a se deslocar para além de nossas fronteiras nacionais. Essas migrações continentais também mostram o deslocamento de frentes formadas por segmentos variados. Constituem efetivamente movimentos de migração de trabalho. Fora do território nacional, recriamse elementos da conflitualidade em decorrência da luta por recursos e território.

\section{Modernização empresarial}

No final dos anos 80, os grandes empreendimentos localizados na Amazônia começaram um processo de modernização com mudanças significativas nas relações de trabalho, em especial nos padrões de gestão, o que refletiu no interior da empresa e também na ampliação de um mercado terceirizado. Observa-se mais recentemente a extensão de práticas de subcontratação de serviços menos importantes no processo produtivo, mesmo para atividades antes consideradas típicas do desempenho da empresa principal. No plano da qualidade de produtos e da competitividade do mercado, essas firmas obtiveram vantagens, apesar da grande competitividade do setor no nível mundial. Igualmente, elas se esforçaram para definir estratégias mais adequadas, pressionadas pelas novas regulamentações impostas pela dinâmica do mercado mundial. Mas, a par dessa observação sobre as práticas diretamente implicadas nos resultados da produção, qualidade e competitividade, as práticas colocadas em marcha, no campo das relações com o político, continuam bastante autoritárias. Reconstroem-se representações sobre o trabalho e sobre a gestão de qualidade, noções que se tentam introduzir enquanto dimensão do cotidiano, da sociabilidade fora do trabalho. A hierarquia ocupacional bastante reduzida não esconde, entretanto, a relação autoritária recodificada no processo de trabalho, reatualizando as modalidades de paternalismo nas relações de trabalho.

Isso reforçou também o processo de modernização, a partir da constatação das possibilidades de perda da competitividade, mudando, assim, no âmbito interno, as práticas de gestão, apostando que as mudanças levariam muito tempo, mas poderiam ser progressivas, se feitas sobre a base de uma planificação da gestão. As mudanças tecnológicas ficaram restritas, fundamentalmente, à automação. Possibilitado pela micro- 
eletrônica, em grande parte, o processo de comunicação no interior da empresa potencializou as questões em relação ao processo de trabalho, materiais, estoques, etc. As mudanças foram também efetuadas pela exteriorização de parte do processo produtivo, sob a forma de terceirização e subcontratação de empregados, descentralizando-se decisões e, sobretudo, empregando-se de um método corretivo, novos conceitos e técnicas de organização e controle da produção e da força de trabalho.

Os impactos da modernização sobre a força de trabalho, que se refletem em novas formas de segmentação do mercado, colocam em questão a relação salarial e, portanto, o emprego e a própria noção de trabalho, conforme tem sido discutido na literatura recente sobre reestruturação produtiva. Certamente se está frente a problemáticas bastante diversas, se forem levadas em consideração as particularidades de países e regiões. Porém observa-se que há um movimento de tensão no mercado de trabalho, em que se encontra uma redefinição das antigas regulamentações do contrato de trabalho, tendência à instabilidade do emprego, emergindo outras formas de trabalho precário e de trabalho em domicílio.

Afinal, o que poderia ser interessante na análise da firma e de suas estratégias de modernização? De que maneira a modernização da firma, que se faz pelas pressões do mercado globalizado, pode combinar se, no nível local, com padrões tradicionais de gestão da vida doméstica, na conjugação trabalho x residência? Observa-se, nos casos analisados, que a ideologia da qualidade transita sem grandes desvios da usina à gestão do cotidiano, incorporada nas práticas de ensino, nos serviços prestados às famílias de trabalhadores, tais como as escolas primárias e secundárias, o hospital, o clube, etc., irremediavelmente amarrada a outras noções, tais como racionalidade, limpeza, arrumação, sistematização, surgindo o modelo de gestão da empresa e, portanto, de uma vida quotidiana em que a noção de "qualidade total" pode constituir a ponte entre o sucesso profissional e o social. Essa burocratização do cotidiano é revalorizada nas estratégias da empresa, pelos mesmos padrões pelos quais se constroem os planos de trabalho - rotina - e a vigilância da segurança e do controle da qualidade total.

Tal processo de modernização tem levado a mudanças progressivas nas relações de trabalho dentro da empresa e no espaço extra-empresa, neste caso, particularmente possível pela sedentarização da força de trabalho, em vários casos devido a residência nas vilas das empresas. Caso 
particularmente presente em inúmeras empresas do setor madeireiro (o município de Paragominas é um exemplo clássico) e nas grandes empresas do setor mínero-siderúrgico (Castro, 1989, 1993, 1994) ${ }^{9}$. Está-se diante de um processo de imobilização da força de trabalho pela moradia, diferenciada socialmente (alojamentos e residências) e com elementos de distinção presentes tanto na Vila dos Cabanos (Barcarena), quanto na Cidade de Carajás (Carajás), no Núcleo Urbano (Tucuruí) e no Núcleo Urbano da MRN (Trombetas), constituindo a base fundamental de sociabilidade.

No entanto, o que observamos nas indústrias de alumínio na Amazônia leva-nos a concluir que estamos face a uma problemática mais complexa, na qual a adoção de novos modelos de gestão tem garantido o aumento de produtividade, via conversão de postos de trabalho e transferência para terceiros de atividades antes desenvolvidas pelas empresas. As mudanças verificadas na administração da empresa evidenciam-se pela aplicação de inúmeras técnicas fundadas em novos princípios de racionalidade, procurando-se eliminar desperdício de materiais, alcançar uma produção enxuta, com estoques zero e melhoria da qualidade. Nesse caso, entendemos que há uma adaptação dos modelos de flexibilização às indústrias de fluxo contínuo. Isso pode ser visto pela via da relocalização das plantas no nível mundial, de novos modelos organizacionais ou do intenso processo de terceirização. Nessa perspectiva, as lógicas de flexibilização podem ser examinadas tanto pelo lado da produção e do espaço, quanto pelo das relações de trabalho. Razão pela qual entendemos que as mudanças no sentido da flexibilização interpelam não apenas as relações de produção no interior da empresa, mas é toda a sociedade que é fundada na relação salarial, na medida em que exige profundas reformulações nas formas de regulamentação das relações de trabalho - o contrato de trabalho - e das estratégias do Estado em relação às empresas e ao conjunto de pessoas livres para vendere sua força de trabalho.

\footnotetext{
${ }^{9}$ O que se depreende das análises de casos sobre o que tem sido chamado de "reestruturação produtiva", no Brasil em geral e mesmo em regiões menos industrializadas como a Amazônia, é que as estratégias implantadas não podem ser tomadas como um conjunto homogêneo, monolítico ou caminho de mão única. Ao contrário, se os fins a atingir têm a mesma direção - ganhos de produtividade e de mercado - as estratégias adaptativas e o desdobramento em ritmos ou processos diferentes, têm sido bastante diferentes, percebendo-se a formulação de múltiplas experiências em empresas brasileiras ou de outros países.
} 


\section{Conclusão}

Se, por um lado, através dessas formas de trabalho, um campesinato múltiplo e polivalente encontrado na Amazônia participa da economia nacional, constituindo inclusive parcela significativa na economia regional, por outro lado, cresce em importância a presença nessa região de padrões definidos por empresas de médio e grande porte, inseridas na dinâmica atual do mercado mundial. Permanecem questões instigantes. A modernização das estruturas empresariais e o aparecimento de novos setores da economia regional estariam enfraquecendo as relações paternalistas no âmbito do trabalho? O que muda essencialmente na forma trabalho e na dominação social? Inúmeros estudos têm apontado a reprodução de formas autoritárias de poder no seio do campesinato, o que não exclui a presença também de avanços políticos desse segmento, e uma modernização conservadora em médias e grandes empresas. Nesse caso, contrariam os discursos sobre participação e qualidade total nos quais as empresas se ancoram para implementar a reestruturação produtiva e os novos padrões de gestão. Mas como entender de que forma se dá a associação dessas empresas modernas, na cadeia produtiva, com pequenas empresas que mantêm formas tradicionais e precárias de trabalho? Quais as lógicas e interesses que orientam a articulação desse conjunto de empresas - grandes, médias e pequenas - com os produtores familiares? Como se tecem as relações de dominação e de acordo com que modalidades de paternalismo? Isso vem ocorrendo em vários setores da economia e em que momentos do processo produtivo? Questões que se desdobram e que reforçam a tese da revisão da noção de trabalho.

Certamente no extrativismo de recursos naturais encontram-se elementos de explicação, em especial nos setores madeireiro, pesqueiro, de mineração e de frutas e sementes nativas. Esses empreendimentos integram-se, porém, ao mercado mundial mantendo padrões exigidos de qualidade e competitividade, renovando estratégias de controle de qualidade nos mesmos processos produtivos. No caso de grandes empresas do complexo do alumínio, eles optaram por um modelo de gestão centrado nos conceitos de qualidade e segurança, introduzindo um planejamento estratégico com o objetivo de alcançar práticas participativas dos trabalhadores. Tanto as médias quanto as grandes empresas perfilam-se no campo comum da reatualização do extrativismo na região, embora com a incorporação de novas bases tecnológicas e organizacionais. 
Como tentamos mostrar, a compreensão sobre os domínios territoriais em regiões periféricas como a Amazônia requer primeiro que se reconheça o princípio da complexidade e, nesse paradigma, que se tente compreender a diversidade de processos de trabalho, de modalidade de gestão e de relações de dominação. Para o setor empresarial, parece significar a montagem de novas estratégias de territorialidade, formulando projetos tanto para o uso imediato de recursos quanto para o estabelecimento de reservas na expectativa de processos futuros de valorização.

Talvez aí resida um campo de estudos sobre o trabalho fértil que dê pistas para entender por que, em regiões periféricas, as metamorfoses do trabalho e o avanço da relação salarial passam por dinâmicas que não implicam necessariamente processos de modernização. Mas apesar disso, a modernidade é o contraponto da tradição. Ao contrário, as relações entre processos tradicionais de trabalho e os empreendimentos têm reafirmado princípios ancorados em formas de autoridade social arcaica e altamente desiguais do ponto de vista do usufruto dos recursos do território. Inúmeros estudos colocam em evidência figuras de autoridade social e política que reeditam, no presente, formas sociais de dominação exercidas diretamente nos lugares de trabalho ou mediadas por vários níveis do mando político. Essas modalidades de dominação estendem-se ao longo de diferentes processos de trabalho e cadeias produtivas, embora sem a mesma intensidade em cada uma de suas partes. Elas precisam ser compreendidas em suas raízes que extrapolam certamente o âmbito do trabalho, daí porque essa análise vai além da relação assalariada, pois circula do trabalho extrativo ao industrial. Interpela a própria noção de trabalho e a constituição dos campos da dominação social, na sociedade brasileira. A análise das particularidades dessa região iluminam, de certa forma, processos que têm configuração e âmbito nacional, sobre formas de trabalho diferenciados.

\section{Bibliografia}

ABREU, A et al (1997). Produção flexível e relações interfirmas: a indústria de autopeças em três regiões do Brasil. Rio de Janeiro (mimeo)

ACEVEDO, Rosa \& CASTRO, Edna (1998). Negros do Trombetas. Belém, Editora CEJUP - $2^{\circ}$ ed.

ACEVEDO, Rosa \& CASTRO, Edna (1999). Relatórios da Pesquisa Mapeamento de Comunidades Negras Rurais no Estado do Pará. Belém, NAEA/UFPA. 
ALMEIDA, Alfredo W.B. (1986). Estruturas fundiárias e expansão camponesa. In: Gonçalves Jr., José M. (org.). Carajás: desafio político, ecologia e desenvolvimento. São Paulo, CNPq/Ed. Brasiliense.

ARAÚJO, Roberto (1994). Manejo ecológico, manejos políticos: observações preliminares sobre conflitos sociais numa área do Baixo Amazonas. In: D’Incao, Maria Ângela \& Silveira, Isolda Maciel. A Amazônia e a crise da modernização. Coleção Eduardo Galvão. Belém, MPEG.

BOURDIEU, Pierre (1988). Esquisse d'une théorie de la pratique. Paris, Seuil.

CASTRO, Edna (1994). Industrialização truncada: globalização e pós-fordismo. In: Aragón, Luis E. What Future for the Amazon Region? Institute of Latin American Studies. Stockholm University.

CASTRO, Edna (1997). Racionalidade e novos padrões na gestão do trabalho em grandes empresas na Amazônia. In: Magalhães, S., Brito, R. \& Castro, E. Energia na Amazônia. MPEG/UFPA/UNAMAZ.

CASTRO, E.; Moura, E. \& Maia, M. L. S. (1995). Industrialização e grandes projetos. Belém, UFPA.

CASTRO, Edna \& PINTON, Florence (1998). Faces do Trópico Úmido. Belém, Editora CEJUP.

DESCOLA, Philippe. Ecologia e cosmologia. In: Castro, E. Pinton, F. Interfaces do Trópico Úmido. Belém. UFPA/CEJUP (no prelo).

DIEGUES, Antônio Carlos (1994). O mito moderno da natureza intocada. São Paulo, NUPAUD/USP.

FAULLHABER, P. (1987). O navio encantado. Etnias e alianças em Tefé. Coleção Eduardo Galvão, Belém, MPEG.

FURTADO, Lourdes (1980). Curralistas e rendeiros em Marudá: São Paulo, USP (Tese de Mestrado).

GEFFREY, Christian (1995). Chroniques de la servitude en Amazonie brésilienne. Paris, Éd. Karthala.

GEERTZ, Clifford (1986). Savoir local, savoir global. Les lieux du savoir. Paris, PUF.

GIDDENS, Anthony (1991). As conseqüências da modernidade. São Paulo, UNESP.

GODELIER, Maurice (1981). A racionalidade dos sistemas econômicos. In: Carvalho, Edgar de (org.) Godelier. Antropologia. Coleção Grandes Cientistas Sociais. São Paulo, Ed. Ática. (1984). L’idéel et le matériel . Paris, Ed. Fayard.

HABERMAS, J. Teoria de la Acción Comunicativa. Racionalidad de la acción y racionalización social. Buenos Aires, Ed. Taurus. 
HARVEY, David (1993). Condição pós-moderna. São Paulo, Ed. Loyola.

HYRLEY, Jorge (1933). No domínio das águas. Livro dos pescadores paraenses. Pará, Belém Typographia do Inst. D. Macedo Costa.

LEITE, Márcia de P. (1994). Modernização tecnológica e relações industriais no Brasil: o quadro atual. In: Gitay, Leda (org.) (1994). Reestructuración productiva, trabajo y educación en America Latina. Campinas CHD-CENED/UNESCOOREALC.

LÉNA, Philippe (1988) Diversidade da fronteira agrícola na Amazônia. In: Aubertin, Catherine (org.). Fronteiras. Brasília/Paris, UnB/ORSTOM.

LIMA, Deborah M. (1997). Equidade, Desenvolvimento Sustentável e Preservação da Biodiversidade: algumas questões sobre a parceria ecológica na Amazônia. In.: Castro, E. e Pinton, Florence. Interfaces do Trópico Úmido. Belém. UFPA/CEJUP (no prelo).

LIPIETZ, Alain (1988) Miragens e Milagres, Problemas da Industrialização no Terceiro Mundo. São Paulo, NobeI.

McGRATH, David et al. (1998) Manejo comunitário de lagos de várzea e o desenvolvimento sustentável da pesca na Amazônia. Revista Novos Cadernos NAEA. VoI. 1 No. 2. NAEA- UFPA, Belém.

MORIN, Emilio (1990). A Ecologia Humana das Populações Amazônicas. Rio de Janeiro. Ed. Vozes.

OLIVEIRA, Francisco de (1997) Para além do princípio do mercado. Revista Latinoamericana de Estudios deI Trabajo. ALAST. Ano 3, nº. 6, São Paulo.

PICARD, Jacky (1994). O Clientelismo nas Colônias Agrícolas do Sudeste do Pará. In: D’Incao, Maria Ângela \& Silveira, Isolda Maciel. A Amazônia e a crise da Modernização. Col. Eduardo Galvão. Belém, MPEG.

RUAS, Roberto (1994) Reestruturação Sócio-econômica, Adaptação das Empresas e Gestão do Trabalho. In: Gitahy, Leda (Org.) Reestructuración Produtiva, Trabajo y Educación en America Latina. Campinas.

ROUÉ, Marié (1997) Novas perspectivas em etmoecologia: "saberes tradicionais" e gestão dos recursos. In: Castro, E. \& Pinton, F. - Faces do Trópico Úmido. CEJUP. Belém.

THOMPSON, E. P. (1987) A Formação da Classe Operária Inglesa. Tomo II. A Maldição de Adão. Rio de Janeiro. Paz e Terra.

Paz e Terra. (1987) Senhores e Caçadores. São Paulo. Oficinas da História.

WOMACK, J.P., JONES, D. L, ROOS, D. (1992) Le Syltéme Qui va changer le monde. Dunod. Paris. 